ment. Moreover, all the necessary adjustments of the diaphragm and specimen can be made in vacuo from the outside. The joints are ground and polished flats held in contact by the atmospheric pressure, a point of importance in routine work where quickness in changing specimens is essential. In this instrument the specimen can be exchanged and the system evacuated in a matter of minutes. Only one criticism $\rightarrow$ minor one - can be made. The shape and size of the window are such that the eyes must be held quite close if the whole pattern is to be seen, and the screen is then rather near for comfortable vision. Suitable pumps are supplied, a variety of systems being available to suit individual needs, or a standard unit is made up ready for use. This instrument is noteworthy as it marks the entry of the diffraction camera into the industrial research laboratory, where it should yield valuable information upon metallic surface structure, to mention only one of the many possible industrial fields of investigation.

\section{Energy obtained by Transmutation}

Mr. Robert D. Potter, of 'Science Service', Washington, D.C., points out that the confirmation of the artificial breakdown of uranium announced in New York (see also Nature, Feb. 11, p. 233) is in the direct succession of experiments carried out in recent years on the transmutation of the elements. For centuries, alchemists had dreamed of transmuting base metals into gold. It was imagined that enormous wealth would be at hand for the discoverer of this transmutation, and dire forecasts of the effects of this discovery were made, such as a complete revolution on the financial pattern of the world. We know that this transmutation has now been achieved for most of the known chemical elements. Transmutation's biggest result is the theoretical incentive it has provided for further physical researches. In a similar way, the dream of releasing the large amounts of energy locked inside atoms has been in the minds of men for many years. When the most efficient transformation of energy takes place in the atom of uranium so that a neutron can slip into it, the energy released is only one fifteenth of that required to bring it about. In fact, neutrons are so easily absorbed by all atomic nuclei that many of the neutrons produced with such poor efficiency will only go into atoms other than uranium. There need be little fear of an explosion in Nature due to uranium. The very heavy elements, in which such an energy release can be secured, occur only in very small amounts in the earth's crust. The release of atomic energy can only be achieved by direct experiment with this end in view and with elaborate laboratory apparatus.

\section{Archæological Discovery near Hove}

A somewhat remarkable find of traces of what would appear to be an ancient settlement is reported from the neighbourhood of Hove (The Times, February 20). The discovery has been made on the downs, north of Hove, where the existence of such remains had not previously been suspected. It is thought that they may be Roman, possibly of the first century A.D. The discovery was made on February 17 by a Corporation labourer who unearthed a collection of pottery, less than eighteen inches from the surface, when digging sewer trenches on a municipal housing estate. A further find was an earthenware vessel filled with about 450 small bronze coins, on some of which the head of a Roman emperor has been distinguished, but of a date not yet estab. lished. It is thought that the settlement, which overlooks Hove from the hills, may have been established about A.D. 50 and have lasted until the third century. The site is being investigated by Mr. H. G. Massey, curator of the Hove Museum, with the assistance of Dr. Cecil Curwen.

\section{Earthquake in Bulgaria}

ON February 17, an earthquake of considerable intensity was experienced at Gornadjoumaja and Sofia in western Bulgaria. At the same time a strong roaring sound was heard, and many people fled from their homes, though no serious damage or easualties are reported. The epicentre of the shock may have been about fifty miles south of Sofia, where there is the most pronounced seismic centre in Bulgaria. Between the years 1749 and 1936, 1,420 earthquakes had their epicentres in this region, and one at least had an intensity greater than 7 on the Rossi-Forel scale. The most disastrous shocks in Bulgaria in recent years were those of April 14, 17, 18, and 21, 1928, which were felt at Chirpan and Plovdiv and did more than $£ 4,000,000$ damage.

\section{Science and Society}

The Division for the Social and International Relations of Science of the British Association is arranging a programme of meetings at which topics of immediate interest and importance will be discussed. The first of these meetings will be held on March 28 at the University of Reading, when two sessions will be devoted to a discussion on "Milk in its Nutritional and Allied Aspects". The chairmen of the sessions will be Sir Richard Gregory and Sir Daniel Hall. Other speakers will deal with deficiencies of diet, health aspects, pasteurization, production, cost, economic and social implications. It is also proposed to arrange meetings in the early summer in London and Manchester for review of the social relationships of science, and for discussion with special reference to pressing problems in industry and agriculture. In connexion with the Manchester meeting, Prof. $H$. Levy has been appointed to deliver the Alexander Pedler Memorial Lecture in which he will explain the method of approach in the study of the social problems of science, with particular illustrations of the application of scientific discoveries to industry. During the forthcoming meeting of the British Association in Dundee (August 30-September 6), the Division will hold three sessions when it is proposed to consider the co-ordination of scientific research, population movements and nutrition. Sir Richard Gregory, chairman of the Division, and lately editor of Nature, will deliver an address on "Science and Social Ethics". 